distinguished representative of medical science, the lecture to be described by a distinctive title. By this means posterity will be reminded of their inclebtedness, a rallying occasion of interest will be provided for the Fellows, and, following the steps of enterprise, the Society could not fail to gain advantages by such evidence of adrlitional and continuing vitality. I am, Sir, yours faithfully,

Wimpole-street, W., Dec. 7th, 1912.

Peruy DunN.

\section{THE RADIUM INSTITUTE AND THE TREATMENT OF CANCER.}

\section{To the Editor of THE LANCET.}

SIR, - The Radium Institute, founded at the suggestion of King Edward three years ago by Sir Ernest Cassel and Viscount Iveagh, was formally opened on August 14th, 1911, and its work of scientific research and the skilled application of radium in the treatment of disease commenced. The medical press stated that the institute had stored in its building a larger supply of radium than was possessed by any other institution in the world, and THE LANCET hesitated to estimate in terms of pounds, shillings, and pence the commercial value of the precious element at 16, Riding House-street, Portland-place. The interests of the patients and of medical practitioners generally are safeguarded by certain regulations, and the scale of charges fixed 2 guineas for the first consultation, and 2,4 , or 5 guineas for each treatment or sitting according to the amount of radium used and the situation of the lesion. The "sitting" might last several hours, and necessitous patients, so certified by their medical adviser, were granted free treatment. The institute has accommodation for the reception, examination, and temporary treatment of patients, in addition to modern laboratory equipment for research, chemico-physical, photographic, and other work.

What provision has, however, been made to place the resources of the institute at the service not only of those whose infirmity may prevent their coming in person to be treated, but also of those who may be suffering from an inoperable lesion, and to whom radium alone holds out hope? Research is going on all over the world as regards the effect of radium in malignant tumours that are beyond the resource of surgery, and the Radium Institute, with the vast amount at its disposal, should surely lead in that research. So long, however, as the radium is not allowed to be removed from the institute, and there is no ward or room accommodation in the institute for the admission and proper treatment of such patients, research on these lines is impossible. For such research must frequently imply the introduction by operation of tubes containing radium into the actual substance of the tumour-that is to say, the coöperation of the surgeon and the radium specialist in the hospital ward. Until such coöperation can be obtained, the Radium Institute must fall far short of the success it might otherwise obtain.

Far the best and simplest solution of the difficulty and the correction of what must be an oversight would be the utilisation of the hospitals already existent. Surgeons, for example, in the London or Guy's Hospital, or private practitioners with patients suffering from inoperable malignant risease, would call the radium expert in consultation to advise as to the application or the insertion of the radium which the institute would, upon due guarantee, temporarily supply. There can be no serious objection to such a method, which has been followed for years on the Continent. Its advantages, on the other hand, are evident, for the knowledge of the value of radium in such cases would be more widely spread in the profession, and a far greater utility would be given to the invaluable amount in the possession of the institute.-I am, Sir, yours faithfully,

$$
\text { A. A. WARDEN, M.D. }
$$

Visiting Physician Hertforl British Hospital, Paris. Paris, Dec. 14th, 1912.

* "If by any chance the supply of radium were lost it might be impossible to replace it for a long time-one or two years. For this reason we understand the regulation was made not to allow the radium to be removed from the buildings of the institute.-ED. L.

1 The Lancet, August 5th, 1911, p. 396.

\section{DRUNKENNESS AND THE EFFECT OF} ALCOHOL.

To the Editor of THE LANCET.

Sir,-May I, on behalf of the temperance workers in the country, thank you most cordially for publishing in your issue of Nov. 30th Dr. Mercier's amusing address? The air of boyish irresponsibility which characterises it is refreshing in these sober times, and although it will doubtless be quoted freely in the liquor trade journals, it is not likely to be treated generally as a serious contribution to the literature on the alcohol question.

Dr. Mercier at the beginning of his address says that he "finds it difficult to believe that the craving for using exaggerated language about it [alcohol] might not be resisted and surmounted by the exercise of self-control," but by the time he had finished it he must have realised that there were, at any rate, a few cases where the craving for using exaggerated language about alcohol was irresistible and beyond self-control. Every now and again we come across these outbursts, and for the next few years Dr. Mercier's address will be a loous classicus on the subject of the intemperate advocacy of alcohol.

The immediate reason for this letter was, however, to call attention to the serious, indeed astounding, inaccuracy of Dr. Mercier's figures as to drunkenness in this country. Dr. Mercier says that there are "80,000 drunks out of some 32 millions," and in answer to the suggested criticism that "there is an immense number of drunkards that escape conviction" he asks: "Where do you get your information? Many, very many, of these convictions are convictions of the same person over and over again "; and so, assuming that every person is convicted twice--he brings down the figure to 40,000 , which is, of course, one person in 800-and not 8000 as he states.

"Where," I ask, "does he get his information"? It is absurdly inaccurate. Here are the facts for England and Wales taken from the Licensing Statistics of 1911 recently published. The total number of "Proceedings" was 195,935; these resulted in 172,130 "convictions"; and, after eliminating previous convictions, the total number of separate "persons convicted" was not 40,000 , but 153,084 , or not 1 in 8000 or 800 , but 1 in every 236 men, women, and children ! - a very different story.

Surely, Sir, it is due to your great profession and to the public that men who speak on this vital question should make themselves acquainted with the elementary facts of the problem, or, if acquainted with them, should not misstate them. The medical profession can best judge of the scientific value of Dr. Mercier's address, but perhaps a humble layman who has given some attention to the statistics of this question may venture the comment that if $\mathrm{Dr}$. Mercier's scientific opinions rest on no surer foundation than his statements of fact, they are unworthy of acceptance by a profession whose very utility to the world depends on its accuracy of observation and soundness of deduction.

\section{I am, Sir, yours faithfully,}

GEORGE B. WILSON,

Secretary of the United Kingdom Alliance.

Manchester, Dec. 11th, 1912

PS. - I have now seen Dr. Mercier's announcement in your issue of Dec. 14th. He did not hesitate to make certain inaccurate statements on matters of fact which were well within his means of knowledge. He withdraws these statements, after they have been scattered broadcast throughout the country and served their purpose. I wonder what he would have said if a temperance advocate of standing had acted in the same way?

\section{THE SANATORIUN BENEFIT IN IRELAND.}

\section{To the Editor of THE LANCET.}

SiR,-The writer of your Irish letter in last week's issue of THE LANCE'T (p. 1683) draws attention to many of the difficulties which hamper the administration of the sanatorium benefit in Ireland. The Irish Insurance Commissioners have put forward a further legal difficulty, which almost ties the hands of Insurance Committees in regard to the provision of domiciliary treatment. The Commissioners, acting on counsel's opinion, declare that a Committee in making arrangements for domiciliary treatment under the sanatorium benefit must make all 